\title{
THE REFUGEE AND MIGRANT CRISIS IN MACEDONIA ASSOCIATED WITH DISASTER RISK MANAGEMENT
}

\author{
Vasko POPOVSKI, M.A. \\ $\mathrm{PhD}$ candidate in security studies, \\ Faculty of Philosophy - Institute of Security, Defense and Peace - Skopje \\ Email: vasko.popovski.vp@gmail.com \\ Stevko STEFANOSKI, Dr. \\ Crisis Management Center \\ Email: stevko.stefanoski@cuk.gov.mk
}

\begin{abstract}
:
Refugee and migrant crisis is a global problem not only for the Republic of Macedonia and the Balkans, but the whole Europe. The Republic of Macedonia is one of the key points of the Balkans route of movement, mainly from the Middle East, Arab states and North Africa to countries in Western Europe. During the first half of 2015, the country was faced with a mass influx of refugees and migrants who entered from neighboring Greece. This situation caused a disruption of public order and security in the cities, especially in the southern and northern parts. Therefore it was needed to undertake coordinated and organized action and the Government on 19.8.2015 adopted a Decision declaring the crisis situation in the southern and northern borders. Two temporary reception and transit centers near Gevgelija and Kumanovo (Tabanovce) were established for organized transit through Macedonia. Approximately 888,500 refugees and migrants transited through the territory of the country in the past period. They were provided with maximum support in their reception, temporary accommodation, organized transportation, food, clothing, medical assistance and other services.

On their way to Europe, they are subject to numerous risks and dangers, including natural disasters and accidents. Likewise, the composition of arriving mixed migration flows encompass a wide range of vulnerable migrants, refugees, unaccompanied and separated children and others, with the majority facing serious protection concerns. Experience in managing this crisis imposes the need for their increased awareness about the risks that deriving from local environment (e.g. natural disasters, meteorological hazards, technical - technological hazards and risks of epidemics and infectious diseases). On 14 March 2016 in proximity to the Transit Centre in Cevgelija, amid heavy rain and flash flooding form "Suva Reka" river, during mass movement of a large group of refugees and migrants, 3 persons drowned. In addition, during the pre-crisis period more than
\end{abstract}




\section{Security}

20 casualties were registered during their irregular movement along the railway tracks or from other incidents. There is an evident risk of health character from infectious diseases that they carry to the territory of Macedonia and beyond.

Because of the comprehensive management processes of migrant and refugee crisis within the Crisis management system of the Republic of Macedonia there is an inevitable need of mainstreaming measures and activities associated with disasters risks reducing.

Keywords: refugees, migrants, crisis management, risk, distress risk management.

\section{BACKGROUND}

The year of 2015 was a specific one with unprecedented humanitarian and security crisis in the recent history. Huge number of people on move resulted in millions of people arriving in Europe and knocked-outing the security systems of the countries in the routes. More than a half of them were escaping from the war thorn Syria, whether the others were starting their journeys in Afghanistan, Iraq and Pakistan and in cases of economic migrants from Southeast Asia or Africa. All of them have had only one destination in their minds - Western Europe for securing their security and financial existence.

These movements were characterized with unusual dynamics and patterns. Firstly, waves of movement of groups of men reached the Europe's shores ensuring the "passability" of the routes and over the year more and more families and women with children started to arrive. With this the vulnerability of the refugees and migrants drastically changed, as well as needs for provision of different humanitarian services.

The Republic of Macedonia is a landlocked country in the Balkan Peninsula, in South East Europe. Its specific location and closeness to the Aegean Sea, placed it as an important point in the so called "Balkan Route" for movements of refugees and migrants from Asia, Middle East and Northern Africa. The main artery was flowing from Turkey, through Greece, Macedonia, Serbia and Hungary to Austria and Western Europe. Once the borders of Hungary were "sealed" during the summer of 2015, the flow of refugees and migrants was diverted through Croatia and Slovenia.

\section{THE REPUBLIC OF MACEDONIA IN THE CONTEXT OF REFUGEES AND MIGRANTS' PROCESSES}

The refugees and migrants' crisis is a global problem which are considering not only the Republic of Macedonia and the region of Western Balkan, but broadly the whole European Continent. During the last decades, there were minor movements of refugees and migrants from different parts to Europe and through the Republic of Macedonia, but the summer of 2015 was a specific one where on a daily basis huge thousands of them have arriving on the southern border with Greece. These movements were the largest ones that Europe witnessed for decades. Approximately 1.1 million of refugees and migrants arrived on the European shores, whether 687,000 


\section{Securility}

people arrived at the Southern border of Macedonia with Greece during the period June - December 2015. Originally 79 per cent of people arriving were men, but from June onwards the number of women and children increased. (UNICEF, 2016).

With drastic growth of number of refugees and migrants that were entering and transiting the country daily, also the security and humanitarian issues were increased. There were number of cases of illegal trafficking in people, illegal transportation of refugees and migrants through the territory of the country, their illegal accommodation in so called "transit spots" by organized crime groups etc. On the other side, there were 25 cases of deaths and many injuries based on the railway accidents, since the refugees and migrants mainly followed the railway tracks in order not to be noticed by the Police, as well as other incidents with death or injuries during their hiding from national and local authorities.

Accordingly, the Government of the Republic of Macedonia modified the Law on Asylum and temporary protection allowing them a free transit for period of 72 hours. This action led to slight decrease of the criminal acts related to illegal trafficking in persons, as well as tragic accidents. However, intensified movements in the region led to more and more refugees and migrants that would have arrived at the border. Increased presence of the refugees and migrants and their contacts with the local population led to specific attitude to be developed by the local population towards them. It ranged from humanitarian support to not friendly attitude and insecurity of the local population. Especially during the summer period (July - August) increased number of refugees and migrants resulted in breaking of the public security and endangered the security condition in the cities and villages alongside the Southern bored, especially on the territory of the Municipality of Gevgelija. There were many cases of attacks and damages on private property, degradation of the environment and breaking of public security. These events and staggering number of refugees and migrants led to a point when the country could not react with conventional resources to the increased number of refugees and migrants and to provide them with the adequate protection as per the international conventions. There was a need to implement coordinated and organized measures for tackling this situation.

Accordingly, on the proposal of the Assessment Group and the Steering Committee within the framework of the Crisis Management System, the Government of the Republic of Macedonia on its session on 19 August 2015 declared a crisis situation on the part of the territory of the Republic of Macedonia, on its Southern and Northern border on the territories of the municipalities of Gevgelija and Kumanovo. In accordance with the decision, the Crisis Management Centre took over the national coordination for management of the crisis and developed an "Action Plan for prevention and management of entry and exit of refugees and migrants through the territory of the Republic of Macedonia". With this Action Plan following aspects were regulated: modality of participation and activities of all relevant national and local institutions, as well as the international community and civil societies in providing support to the efforts of the national capacities.

Per the Law on Crises Management, the Government adopts the decision on the existence of a crisis, it determines the area affected by the crisis and it accordingly activates the mechanisms for resolving the crisis. The Government decides on the use of resources of the state bodies, mu- 


\section{Security}

nicipalities and the City of Skopje, as well as managing them in case of crisis. In the event of a crisis, the resources of public enterprises, establishments and service providers, and trade associations are of importance for working in critical conditions. In these cases, at the request of the Government, based on the agreement concluded with the Crises Management Centre or voluntarily, the resources of private citizens and legal entities can be used to help resolve the crisis. The proclamation of the crisis situation invoked the involvement of the Crises Management Centre. Due to early warning, i.e. monitoring the situation, timely identification of phenomena and processes that pose risks and threats to the security of the state, which may lead to a crisis situation, the Crisis Management Centre informs and alerts the participants in the Crises Management System and the public. Moreover, the Crisis Management Centre has already developed capacities which required adjustment and improvement in regards to the specifics of this crisis situation.

The Crisis Management System is organized and conducted for prevention, early warning and crisis management that pose a risk to property, health and life of humans and animals caused by natural disasters, epidemics or other risks and dangers that directly threaten the constitutional order and security of Macedonia. This system includes gathering information, assessment, analyses of the situation, establishing goals and objectives, developing and implementing the necessary actions for prevention, early warning and crisis management. The Crises Management Centre performs activities related to ensuring continuity in the inter-departmental and international cooperation, consultations and coordination in crisis management; preparation and updating of a unified assessment of risks and threats to the security of the state; proposing measures and activities for resolving crises and performs other duties prescribed by law.

For the purposes of implementation of organized transit through the territory of the Republic of Macedonia and in cooperation with relevant international organizations (United Nations High Commission on Refugees - UNHCR and others) and civil society organizations, two temporary transit centers were established on the southern border near Gevgelija - "Vinojug" and on the northern border near Kumanovo - "Tabanovce". They served as entry and exit points for acceptance, evidence, registration, issuance of certifications for declared intention of asylum, preparation of the refugees and migrants for transit through the territory of the country and for support of the exit of the country to Serbia. During the past period from the beginning of the refugee and migrants' crisis until now, approximately 800,000 registered refugees and migrants transited the territory of the country. They were provided with maximum support during their acceptance, temporary accommodation, organized transportation, food, clothes, health support and other services.

Due to the continuity of the refugee and migrants' crisis as well as the risk for additional inflow of refugees and migrants, the crisis situation was extended for two additional periods, until 31 December 2016, and until 30 June 2017.

Experiences from the management of the refugees and migrant's crisis impose the need for increasing the awareness of the refugees and migrants on the local environment (risks form natural disaster, meteorological hazards, technical-technological hazards and risks from epidemics 


\section{Security}

and infectious diseases) while they are transiting through the country. Considering this it is good to state two examples of mentioned relation. On 14 March 2016, in the vicinity of the Transit Center "Vinojug" near Gevgelija, in the event of torrential rain and flash flooding from the local "Suva Reka" River, during the mass movement of the bigger group of refugees, three people were drowned (one male and two females), whether 23 people from the group were rescued by the Police and rescuing forces. In addition, during the pre-crisis period more than 20 casualties were registered during their irregular movement along the railway tracks or from other incidents. There is an evident risk of health character from infectious diseases that they carry to the territory of Macedonia and beyond. Based on reports by the World Health Organization, the most frequent health problems of arrived refugees and migrants to Europe include accidental injuries, hypothermia, burns, gastrointestinal illnesses, cardiovascular events, pregnancy- and delivery-related complications, diabetes and hypertension. Vulnerable individuals, especially children, are prone to respiratory infections and gastrointestinal illnesses because of poor living conditions, suboptimal hygiene and deprivation during migration, and they require access to proper health care. Poor hygienic conditions can also lead to skin infections. Migrants often come from communities affected by war, conflict or economic crisis and undertake long, exhausting journeys that increase their risks for diseases that include communicable diseases, particularly measles, and food- and waterborne diseases. As reported by IOM mobile teams and Macedonian Red Cross in their daily data capture and interventions, the most common illnesses are respiratory diseases, gastrointestinal and locomotor disorders, dermatitis/ wounds. Red Cross analyzed a 9-day period during the second half of October 2015. The number of interventions during this period was 6.800 (approximately 755 per day) and the statistics were the following: respiratory diseases $-42,7 \%$, gastrointestinal diseases $-13 \%$, wounds $-8,4 \%$, dermatitis $-7,9 \%$, locomotor $-7,9 \%$, etc.

\section{DISASTER RISK REDUCTION CONTEXT OF THE REFUGES AND MIGRANTS CRISIS}

All these statements mentioned above, re-confirms the need the crisis management system to provide an adequate information to the refugees and migrants for the hazards that are present on the territories in which they are temporary present or transiting, especially the municipalities of Gevgelija and Kumanovo, as well as through the transit corridor to the Northern border. This information shall be provided in an organized and tehcnically supported modality.

Vice versa, presence of the refugees and migrants on the territoryy of the country and the municipalities, presents additional element of risk based on their exposure and vulnerability to natural and human - made disasters. Therefore, this is needed to be taken into consideration during the analysis and evaluation of possible risks. In general, the issue of correlation between the refugees and migrants and the disaster risk reduction is not being researched thoroughly. Aspects of forced migration induced by disasters were considered and analyzed.

However, the Sendai Framework for Disaster Risk Reduction points to the mobility as a potential element of risk - both the people on move, and for the environment in which they are moving. Migrants are understood to be the key elements of the modern society and they are men- 
tioned in the document in three aspects: governments should engage with relevant stakeholders, including [...] migrants [...] in the design and implementation of policies, plans and standards; empowering local level authorities to coordinate with migrants on local level disaster risk management and using the knowledge and skills of the migrants to contribute to resilience building. (UNISDR, 2015).

\subsection{Disaster Risk Management in the Republic of Macedonia}

The Crisis Management Centre has a normative competence for preparation and update of the Assessment of the endangerment of the territories of the municipalities and the Republic of Macedonia from all risks and hazards. During the period 2011 - 2015, activities for establishment of integrated multi - hazard, multi - risk and multi - sector assessment were implemented with support of the United Nations Development Programme. Accordingly, based on the accepted methodological framework for risk and hazard assessment, risk and hazard assessment documents were prepared for all municipalities in the Republic of Macedonia (80 municipalities + the City of Skopje). Also, the draft version of the National Assessment from all risks and hazards was prepared. The process of preparation of the assessments is completely IT supported one, through the modern web platform "E-Assessment". This platform is connecting all available data basis for existing hazard or hazard profiles of the municipalities, exposure and vulnerability of infrastructure, facilities and population, as well as data on the available resources of the crisis management system.

Municipalities of Gevgelija and Kumanovo have one thing in common, and that is their strategic geographical position on the Southern and Northern parts of the country and that are practically the entry and exit points on the "Balkan Route". This is important aspect of defining their environment and exposure to different hazard.

Based on the analysis of the historical events, as well as impact of the hazards, profiling was done for both municipalities. In Gevgelija hazard profile is consisted of fires, floods, earthquakes, and other hazards, predominantly weather related events (drought, snow falls, storm winds etc.). In Kumanovo, the profiling is the same but with different ranking.

Not all the hazards have same impact on the refugees and migrants that are on the territory on the country or that are transiting through it. Therefore, it is necessary to implement one more layer of assessment and to include them as a part of the environment and element of the risk. They can be most affected by the meteorological hazards having in mind their mobility. At the present situation, earthquakes can do almost no harm, since the existing capacities for temporary accommodation are built from light construction materials or are tents. However, the risk of fires on open places are still present, whether the weather-related events can do most of the harm to them.

Having in mind that they have almost no knowledge of the local environment, local contexts or the local built environment, the level of their vulnerability is being significantly increased. This is multiplied with the characteristics of the refugees and migrants themselves - being women, children or elderly. 


\section{Security}

Therefore, it is necessary to design and develop procedures for their inclusion in the process of risk and hazard assessment, as well as to create tools for basic information sharing on the existing hazards and characteristics of the local environment.

Though, at this phases no inclusion of refugees and migrants are being done on local level risk and hazard assessment neither through profiling nor through planning of information purposes. However, the good example of inclusion of refugees and migrants in disaster risk reduction is the case of the national risk and hazard assessment.

\subsection{National Assessment of all risks and hazards and the issues of refugees and migrants.}

The National Assessment of all risks and hazards is in process of preparation with the draft version of the text being adopted in December 2015. As a document, it is of highest importance for the country, since it is presenting the characteristics of the country and the built environment and population, defining the national hazard profile, as well as assessing and evaluating the possible risks, presenting the available resources and recommending responsive planning.

Based on the approach to profile and prioritize hazards on the territory of the country, refugee and migrants' crisis is elaborated amongst the top ten hazards. This is because of the paramount pressure on the national and local resources as well as possible effects on the national and local security.

Based on the positive experiences from the refugee and migrants' crisis, as well as detected possible threats to the security of the country, there is a separate chapter in the assessment. The refugees and migrants are being considered both in the terms of the general security, but also in the terms of the risk analysis as one of the elements of the risk.

This approach is one of the innovative ones in analyzing the context of the refugees and migrants' crisis in the context of the crisis management and disaster risk reduction. There are recommendations to be incorporated and their inclusiveness in the risk reduction activities is recommended.

\section{CONCLUSION}

Experiences gained from the management of the refugee and migrant crisis in the Republic of Macedonia, raised the need for detection of adequate mechanisms and procedures for integration of these processes in the comprehensive activities for disaster risk management within the framework of the National Crisis Management System. Namely, based on the Law on Crisis Management, the Crisis Management Centre has the competence for preparation and update of the unique assessment of all risks and hazard that can endangered life and health of people, natural and material resources, as well as the general security. This assessment, in terms of its territorial scope, is relevant for the municipalities, the City of Skopje and the Republic of Macedonia.

Based on this aspect, and within the context of this research, three key segments can be defined. The first one is related to the assessments of the municipalities of Gevgelija and Ku- 
manovo, as primarily affected municipalities with refugees and migrants' processes and part of the territory where the crisis situation was declared. The existing assessments prepared by the Regional offices of the Crisis Management Centre and adopted by the municipal councils do not incorporate or recognize the risks of mass movements and massive influx or transit of refugees and migrants from other countries. The second segment is based on the approach that in existing assessments for the two municipalities, all existing risks related to natural and meteorological hazard and technical - technological accidents are assessed and evaluated. However, the specifics of the refugees and migrants as vulnerable category and separate elements of the risk were not translated into the risk assessment process. Furthermore, during the whole process of management of the refugee and migrants' crisis measures and activities for information of refugees and migrants that were entering and transiting the country on the risk environment were not provided.

The third segment is the positive experience regarding the mainstreaming the refugee and migrants' crisis. Based on the existing crisis situation and the experience from 2015, the draft version of the National Assessment from all risks and hazards do recognize the refugees and migrants as another element of risk and elaborates them in the context of the risk evaluation and security of the country.

As a conclusion, this is imposing the need for additional synergy and mainstreaming of the existing documents (assessments, plans etc.) and update and application in the existing and newly originated processes and their correlation for ensuring comprehensive, inclusive and effective crisis management and disaster risk management systems.

\section{REFERENCES:}

Crisis Management Centre. (2015). "Assessment of all risks and hazards (E-Assessment)". http://procena.cuk.gov.mk/Login.aspx?ReturnUrl=\%2f (Visited on 25 April 2017).

Crisis Management Centre. (2015). "Information on the activities of the Crisis Management System in relation with the declared crisis situation on the part of the territory of the Republic of Macedonia during the period 01.01.2016 - 31.12.2016".

http://www.cuk.gov.mk/images/INFORMACII-OD-JAVEN-KARAKTER/2017-INFORMACII-OD-JAVEN-KARAKTER/InormacijazaaktivnostinaSUKvo2016godina.pdf\%20 (visited on 25 April 2017).

Government of the Republic of Macedonia, Crisis Management Centre. (2015) Analysis of declared crisis situation on the part of the territory of the Republic of Macedonia on the regions of southern and northern borders of the Republic of Macedonia, due to the increase volume of entrance and transiting of migrants through the territory of the Re- 


\section{Security}

public Macedonia which are endangering the security, health and property of the population for the period of declaration on 19.08.2015 until 17.09.2015. Skopje: Government of the Republic of Macedonia, Crisis Management Centre.

Government of the Republic of Macedonia, Crisis Management Centre. (2015) Analysis of declared crisis situation on the part of the territory of the Republic of Macedonia on the regions of southern and northern borders of the Republic of Macedonia, due to the increase volume of entrance and transiting of migrants through the territory of the Republic Macedonia which are endangering the security, health and property of the population for the period of declaration on 19.08.2015 until 31.12.2015. Skopje: Government of the Republic of Macedonia, Crisis Management Centre.

Law on Crisis Management $(2005,2011)$. Official Gazette of the Republic of Macedonia No.29/05, 36/11.

Regulation on the Methodology for Preparation of the Assessment of the Endangerment of the Republic of Macedonia from all risks and hazards, its content and structure, modality of storage and update, as well as definition of entities that are receiving whole Assessment or part of it (2011). Official Gazette of the Republic of Macedonia No.13/11.

UNICEF. (2015). Refugee and Migrant Crisis in Europe 2015 - Consolidated Emergency Report.

UNSIDR. (2015). Sendai Framework for Disaster Risk Reduction 2015 - 2030. 